without neurological deficits (57\% vs 26\%). (Camfield C, Camfield P. Preventable and unpreventable causes of childhood-onset epilepsy plus mental retardation. Pediatrics July 2007;120:e52-e55). (Respond: Peter Camfield MD, IWK Health Centre, PO Box 9700, 5850 University Ave, Halifax, Nova Scotia, Canada B3K 6R8).

COMMENT. One in 5 children with epilepsy in Canada is mentally retarded. Two thirds have a prenatal or genetic cause, and only $7 \%$ have an acquired preventable cause. Epilepsy and mental retardation appear to have a common cause, and mental retardation is not the result of the epilepsy. Genetic factors are important in etiology, $50 \%$ of those with no clear cause having a positive family history. The authors comment that the prevalence of a defined cause would probably be greater if the study had involved a later time period when MRI became more readily available.

\title{
PROGNOSIS OF CRYPTOGENIC PARTIAL SEIZURES
}

Factors that influence the prognosis of cryptogenic partial seizures were determined in 233 patients (136 male, 97 female) followed at the outpatient clinic of Shanghai Xin Hua Hospital, Shanghai, China. The mean age of seizure onset was 6 years (range, 3 months to 12 years), and the mean duration of follow-up was 4.5 years (range, 2-13 years). Partial seizures were simple in $41(17.6 \%)$, complex in $162(69.5 \%)$, and complex partial/generalized in 30 $(12.9 \%)$. Antiepileptic drugs were used as monotherapy in 194 patients, and polytherapy in 39 ( 2 drugs in 29 and 3 or more in 10). Response was good in 198 (85\%): complete control in $71.7 \%$, reduction of seizures of $>50 \%$ in $13.3 \%$, and poor or no response in $15 \%$. The prevalence of poor control was correlated with young age of onset $(28 \%$ of 50 children $<3$ years age vs $8 \%$ of $183>3$ years; $\mathrm{P}=0.03$ ). Poor control was also related to seizure frequency $(\mathrm{P}<0.001)$, and seizure type $(\mathrm{P}<0.001)$; control was worse in those with $>3$ seizures/month, and in patients with partial seizures and secondary generalization. No correlation was observed between the location of an EEG focal abnormality and response to therapy. In 24 patients ( $10 \%$ of series) with autonomic symptoms, similar to Panayiotopoulos syndrome, the prognosis was not different from that of patients with motor symptoms. Seizure prognosis was not related to duration of seizure disorder, time to starting seizure treatment, and total number of seizures before treatment. (Wang Z, Qi L, Song X. Prognosis and predictive factors of partial seizures in children. Pediatr Neurol July 2007;37:16-20). (Respond: Dr Wang, Shanghai Children's Medical Center, 1678 Dongfang Road, Shanghai 200127, China).

COMMENT. Young age at seizure onset, a high initial seizure frequency, and partial seizures with secondary generalization are predictors of a poor response to antiepileptic medication in children with partial seizures.

\section{HUMMING AND SINGING IN PARTIAL SEIZURES}

The frequency and anatomic localization of musical automatisms (MA) among 416 patients with partial seizures admitted for video-EEG recording and presurgical evaluation are reported from Timone Hospital, Marseille, France. Seven (1.4\%) patients, 2 children and 5 adults, met criteria for MA. MA consisted of humming in 5 patients and singing in 2 . 
Singing was associated with complex behavioral changes including euphoria, laughing, gestural automatisms, and dancing. Humming occurred in seizures affecting the temporal lobe, whereas singing was associated with scizures originating in the frontal lobe, particularly the right prefrontal cortex. (Bartolomei F, McGonigal A, Guye M, Guedj E, Chauvel P. Clinical and anatomic characteristics of humming and singing in partial seizures. Neurology July 31, 2007;69:490-492). (Reprints: Dr F Bartolomei, Service de Neurophysiologie Clinique, CHU Timone, 264 Rue de Pierre, 13005-Marseille, France).

COMMENT. Musicogenic epilepsy is well known (Critchley M. Brain 1937;60:1327). Seizures occur on hearing or playing music, and often, in response to specific compositions. Laughter as a form of epilepsy (gelastic seizures) is also reported, usually in young children with hypothalamic hamartoma (Mullatti N et al. Epilepsia 2003;44:13101319) (Ped Neur Briefs Nov 2003;17:81-83). Singing as a musical automatism during seizures is uncommon, the above authors citing reports by Vidailher $M$ et al. 1989, and Doherty MJ et al. 2002. The anatomy of music perception has been studied using a highresolution PET scanner at the University of Caen, France, and the Wellcome Department of Cognitive Neurology, London, UK (Platel H et al. Brain 1997;120:229-243). The left hemisphere is dominant for rhythm, tune recognition, and pitch perception, whereas the right hemisphere subserves timbre or quality of tone perception.

\section{ROLE OF $A R X$ GENE IN INFANTILE SPASMS AND DYSTONIA}

The role of $A R X$ gene in a syndrome of infantile spasms with generalized dystonia was investigated in 6 boys from 4 families at the University of Florence, Italy, and other centers in Italy, Japan, and USA. Mutation analysis in 115 boys with cryptogenic infantile spasms found an expansion of the first PolyA tract of $A R X$ in $6(5.2 \%)$ ages 2 to 14 , from four families, including two pairs of brothers. All six had mental retardation and generalized dystonia that developed at 6 months and progressed to quadriplegic dyskinesia within 2 years. Three had recurrent status dystonicus. Multifocal small cavities in the putamina were seen on the MRI of 4 children. ARX gene testing is recommended in boys with infantile spasms and unexplained dyskinetic quadriplegia. (Guerrini R, Moro F, Kato $M$ et al. Expansion of the first PolyA tract of $A R X$ causes infantile spasms and status dystonicus. Neurology July 31, 2007;69:427-433). (Reprints: Dr R Guerrini, Clinical Pediatric Neurology, Department of Pediatric Neurosciences, University of Florence, and Pediatric Hospital A Meyer, via Bonvicini 62, 50132 Firenza- Italy).

COMMENT. Several brain malformations are associated with mutations of the ARX gene, including X-linked lissencephaly with abnormal genitalia, hydrocephalus, and agenesis of the corpus callosum with abnormal genitalia (Proud syndrome). Syndromes associated with the same gene and without brain malformations include X-linked infantile spasms, Partington syndrome (mental retardation with mild dystonia), and X-linked mental retardation. The authors describe an "infantile epileptic-dyskinetic encephalopathy" in males with expansion of the first PolyA tract of $A R X$, and consisting of severe mental retardation, early-onset infantile spasms, and severe progressive generalized dystonia with status dystonicus, some patients showing basal ganglia cysts. 